\title{
Nonoperative management of solitary eosinophilic granulomas of the calvaria
}

\author{
Clinical article
}

\author{
Guillermo De Angulo, M.D., ${ }^{1}$ Sushmita Nair, M.D.,${ }^{2}$ Vivian Lee, M.D. ${ }^{3}$ \\ Ziad Khatib, M.D., ${ }^{1}$ John Ragheb, M.D. ${ }^{4}$ AND David I. SANDberg, M.D. ${ }^{4}$
}

${ }^{1}$ Division of Hematology Oncology, Miami Children's Hospital Cancer Center and Herbert Wertheim College of Medicine; ${ }^{2}$ Department of Pediatrics, Miami Children's Hospital, Miami, Florida; ${ }^{3}$ Department of Pediatrics, Children's Hospital of Los Angeles, California; and ${ }^{4}$ Department of Neurosurgery, The University of Texas Health Science Center at Houston and Children's Memorial Hermann Hospital, Houston, Texas

\begin{abstract}
Object. Solitary eosinophilic granuloma (EG) of the calvaria is most commonly treated with surgical excision. The authors hypothesize that many solitary EGs will resolve without intervention, and observation may be a reasonable option. This study was undertaken to investigate that hypothesis.

Methods. The authors reviewed their institutional records and identified 14 cases of solitary calvarial EG. In 6 cases the patients underwent resection based on family and/or neurosurgeon preferences. A strategy of nonoperative management (purposeful observation) was chosen for the other 8 cases. The authors report the clinical course and imaging results in these 8 cases.

Results. One of the 8 patients underwent surgery 2 months after presentation because of slight enlargement of the lesion and increasing pain. After a median follow-up period of 1 year (range 6-19 months), none of the other patients had required surgery. Five of these 7 patients had pain at presentation. Pain resolved completely in all 5. The remaining 2 remained asymptomatic. Complete resolution of pain was reported in the 5 patients who had pain at presentation. There was complete clinical resolution of the palpable soft-tissue lesion in all 7 cases. Complete radiographic resolution of the lesion was observed in 5 cases and near-complete resolution in the remaining 2.

Conclusions. Observation is a safe and reasonable approach in the management of solitary calvarial EG and may prevent unnecessary surgical interventions.

(http://thejns.org/doi/abs/10.3171/2013.4.PEDS12482)
\end{abstract}

\section{KeY Words • histiocytosis • eosinophilic granuloma • observation • oncology}

$\mathrm{L}$ ANGERHANS cell histiocytosis $(\mathrm{LCH})$ is a disorder characterized by clonal proliferation of cells that resemble dendritic cells and are called Langerhans cells. ${ }^{7}$ The histopathology is defined by staining CD1a positive and by the presence of Birbeck granules on electron microscopy. ${ }^{3}$ The disorder is part of a broad clinical spectrum that includes, at one end, multisystem disease

\footnotetext{
Abbreviations used in this paper: $\mathrm{EG}=$ eosinophilic granuloma; IRB = institutional review board; $\mathrm{LCH}=$ Langerhans cell histiocytosis.
}

and organ dysfunction and, at the other end, solitary eosinophilic granuloma (EG). The natural history and prognosis of LCH are highly variable, depending on the patient's age, multisystem involvement, and involvement of "risk" organs such as liver, lungs, spleen, or hematopoietic system. Eosinophilic granulomas of the bone can be solitary or multifocal and constitute $60 \%-80 \%$ of cases of LCH. The lesions most commonly involve the skull, pelvis, and long bones, with a peak presentation between the ages of 5 and 10 years.

Solitary skull lesions are the most frequent presen- 


\section{G. De Angulo et al.}

tation of EG. While spontaneous remission has been reported previously, ${ }^{11}$ there is no standardized approach to the management of unifocal calvarial EG. Treatment includes surgical curettage or excision, intralesional steroid therapy, radiation therapy, and systemic medications like indomethacin, bisphosphonates, and chemotherapy. Surgical excision is the most common approach at most centers. This study reports on 8 patients who were initially managed with close observation only.

\section{Methods}

After IRB approval was obtained, medical records at Miami Children's Hospital between 2004 and 2011 were queried for the diagnosis of histiocytosis. Patients with solitary calvarial EG were identified. Information about their demographics, presentation, and management was reviewed. Fourteen consecutive patients were identified with solitary calvarial EG diagnosed between 2004 and 2011. All the diagnoses were based on the patients' clinical history and radiological findings of a nonsclerotic "punched-out" lesion with an associated soft-tissue mass. Skull base lesions were excluded. Seven of 8 patients had a CT scan, 1 of these 7 also had an MRI scan, and 1 patient had plain radiographs only. Laboratory studies were performed, including a complete blood count, urine analysis, liver function tests, and a metabolic panel. A skeletal survey was performed to rule out multiple lesions.

\section{Results}

Solitary calvarial EG was diagnosed in 14 patients between 2004 and 2011. Of these patients, 6 underwent resection of the lesion because of the family's and/or neurosurgeon's preference. In all 6 cases, the histopathological examination confirmed the diagnosis of EG.

The other 8 cases were managed with purposeful observation and serial imaging studies (Table 1). One patient (Case 8) underwent a surgical excision after 2 months' observation because of slight enlargement and persistent pain. None of the remaining 7 patients required surgical intervention over a median follow-up period of 1 year (range 6-19 months). The patients were examined with an average of 2 imaging modalities. Two of the 7 patients were asymptomatic on presentation and thereafter; pain resolved completely in the remaining 5 patients. There was complete clinical resolution of the palpable soft-tissue lesion in all 7 patients. In 5 of the 7 patients there was complete radiographic resolution of the lesions (Figs. 1 and 2), and 2 of the 7 patients had a near-complete radiographic resolution.

\section{Discussion}

The clinical manifestations of $\mathrm{LCH}$ are related to the area of involvement, most commonly the bone. ${ }^{8}$ Localized LCH of the bone is a benign tumor-like condition characterized by a clonal proliferation of Langerhanstype histiocytes, and is frequently referred to as EG. It most commonly involves the flat bones of the skull, ribs, pelvis, or sternum. ${ }^{8}$ Calvarial EG typically presents as localized pain and/or swelling and is most frequent in children and young adults. ${ }^{13}$ Diagnosis is usually made by means of skull radiographs, which demonstrate punchedout osteolytic lesions without sclerosis, or CT scan, which allows visualization of the soft-tissue component. ${ }^{9}$ PETCT shows increased uptake in the areas but is not performed routinely.

Treatment for calvarial EG has classically involved excision of the lesion or curettage, depending on the size of the defect. ${ }^{414}$ Spontaneous remission of EG in other sites has been reported, ${ }^{1,3,5}$ but most reports of calvarial EG indicate that the majority of cases are immediately referred for excision. Oliveira et al. ${ }^{11}$ reported 4 cases of calvarial EG in which the lesion resolved even before surgery was performed. In all those cases the lesions increased in size initially and then became smaller and disappeared in a period of 3-4 months. We report 8 cases in which we made a conscious decision to observe in agreement with the patients' parents and neurosurgeons. In 4 cases, the patients were younger than 10 years of age, and in the other 4 , the patients were adolescents. All 8 patients presented with pain and/or swelling of the scalp without skin or systemic involvement. In all 8 cases the diagnosis of EG was made radiographically. Skeletal survey ruled out the presence of other lesions. The lesion resolved completely or nearly completely in 7 of 8 patients, and only 1 patient underwent resection. Resection was performed after 2 months of observation because of persistent pain and slight growth of the lesion, and the patient had no sequelae caused by the delay in treatment. None of the patients whose cases were managed with observation required cranioplasty or had any obvious skull defect.

Although in Case 8 insufficient time was allowed for the lesion to resolve spontaneously in this 18-year-old female patient, the chances of spontaneous remission of EG in other sites is higher in skeletally immature patients than in mature patients as reported by Plasschaert et al. ${ }^{12}$ In their study, these authors found that all lesions in the skeletally immature patients who were below 14 years of age resolved completely without any recurrence even if they were just observed after biopsy without any further treatment.

There have been reports of spontaneous remission in other solid organs ${ }^{5}$ as well. Spontaneous remissions have been reported occasionally in patients with $\mathrm{LCH}$, even with multiple sites of involvement. ${ }^{12}$ Only one prior report, which includes only 4 patients, describes spontaneous resolution of calvarial EG. ${ }^{11}$ The mechanism of spontaneous remission is not clear, but we postulate that there is an immune basis. The lesions of EG are composed primarily of Langerhans cells, which are antigen-presenting cells derived from bone marrow monocytes, but they may also include variable populations of eosinophils, polymorphonuclear cells, and lymphocytes. Older lesions may have a greater degree of fibrosis. Due to immune dysregulation, there is abnormal proliferation of the Langerhans cells. What exactly triggers the proliferation and what causes self-tolerance to break down is still unknown.

In spite of EG being a benign condition and the occurrence of spontaneous resolution, one may be apprehensive about a lytic lesion of the skull because of the proximity to the brain and the lack of a firmly established 
Observation for management of eosinophilic granulomas

TABLE 1: Summary of 8 cases managed with observation

\begin{tabular}{|c|c|c|c|c|c|c|}
\hline $\begin{array}{l}\text { Case } \\
\text { No. }\end{array}$ & $\begin{array}{l}\text { Age (yrs), } \\
\text { Sex }\end{array}$ & Symptom & Site & Size $(\mathrm{cm})^{*}$ & 1st Follow-Up & Most Recent Follow-Up \\
\hline 1 & $4, \mathrm{~F}$ & swelling & rt frontal & $1.8 \times 1.1$ & 3 mos: smaller & $\begin{array}{l}15 \text { mos: resolved clinically \& ra- } \\
\text { diographically }\end{array}$ \\
\hline 2 & $6, F$ & pain \& swelling & rt frontal & $1.3 \times 0.9$ & 3 mos: smaller & $\begin{array}{l}19 \text { mos: resolved clinically \& ra- } \\
\text { diographically }\end{array}$ \\
\hline 3 & $7, \mathrm{~F}$ & pain & rt parietal & $2.2 \times 2.6$ & 1 mo: no change & $\begin{array}{l}7 \text { mos: resolved clinically, nearly } \\
\text { resolved radiographically }\end{array}$ \\
\hline 4 & $12, \mathrm{~F}$ & pain \& swelling & It frontal & $1.2 \times 2.2$ & 3 mos: smaller (clinically) & $\begin{array}{l}6 \text { mos: resolved clinically, nearly } \\
\text { resolved radiographically }\end{array}$ \\
\hline 5 & $15, F$ & pain \& swelling & $\begin{array}{l}\text { rt temporo- } \\
\text { parietal }\end{array}$ & $2.5 \times 2$ & 3 mos: smaller & $\begin{array}{l}1 \text { yr: resolved clinically \& radio- } \\
\text { graphically }\end{array}$ \\
\hline 6 & $15, \mathrm{M}$ & headache & rt parietal & 2.4 & 3 mos: smaller & $\begin{array}{l}1 \text { yr: resolved clinically \& radio- } \\
\text { graphically }\end{array}$ \\
\hline 7 & $2.5, \mathrm{~F}$ & swelling & It parietal & $2.2 \times 1.5$ & 2 mos: smaller & $\begin{array}{l}1 \text { yr: resolved clinically \& radio- } \\
\text { graphically }\end{array}$ \\
\hline 8 & $18, F$ & pain & rt parietal & $1 \times 0.5$ & $\begin{array}{l}2 \text { mos: } 1.2 \times 0.9 \mathrm{~cm} \text {, surgery } \\
\text { performed }\end{array}$ & 1 yr postop: no recurrence \\
\hline
\end{tabular}

* As measured on radiographs or CT scans.

tissue diagnosis., ${ }^{2,10}$ These cases are typically referred to neurosurgeons for resection. The question of whether to subject children with solitary calvarial EGs to surgery and its associated complications when these lesions may resolve spontaneously remains unanswered. We excluded patients with isolated skull base lesions (CNS-risk group) because of the association with diabetes insipidus. Those cases were treated with vinblastine and prednisone as per the LCH III protocol (H-9926-LCH III: Treatment Protocol of the Third International Study for Langerhans Cell Histiocytosis). All of our patients were monitored for worsening of symptoms or any complication caused by extension of the disease. They underwent routine blood counts and blood chemistry analysis at the initial visit and had subsequent close follow-up to monitor for problems such as persistent ear discharge, diabetes insipidus, hepa-
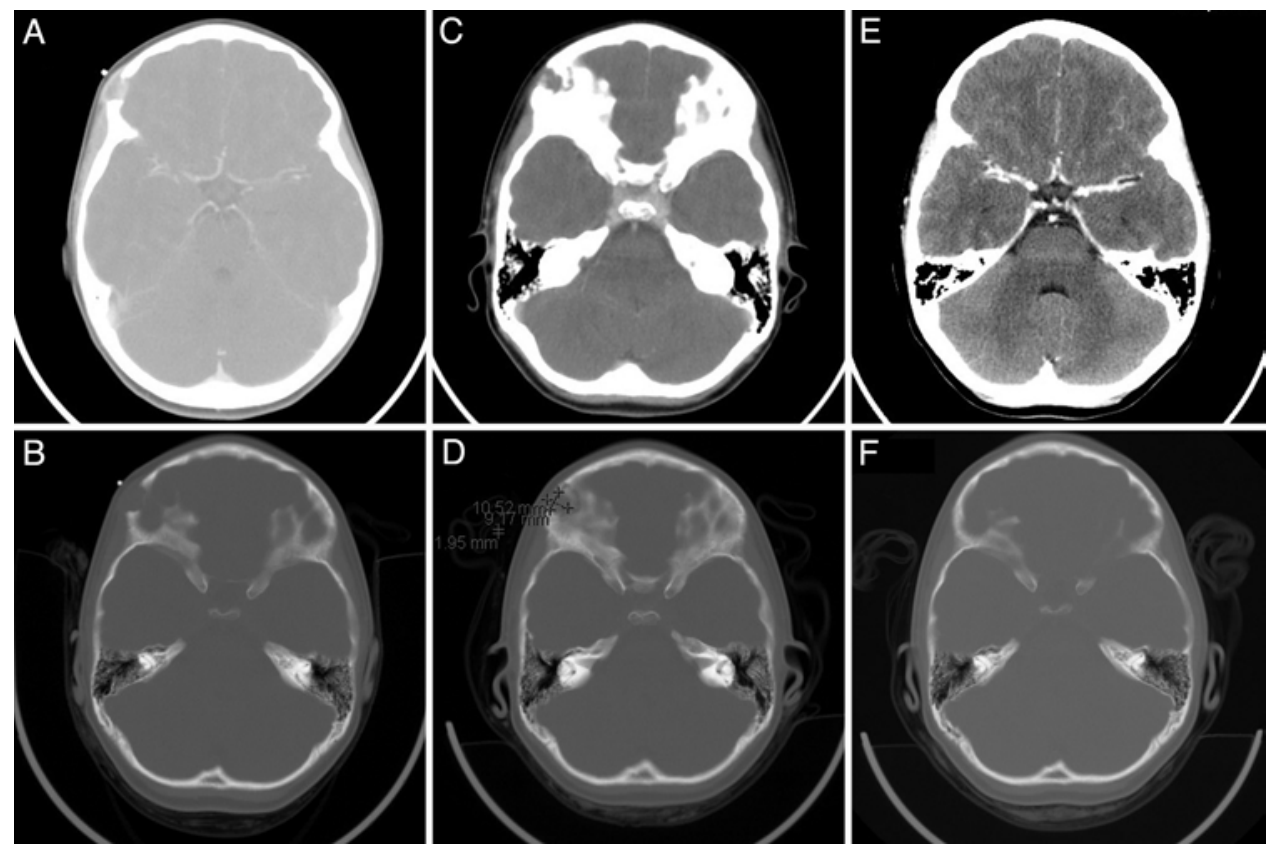

FIG. 1. Serial CT scans obtained in a 6 -year-old girl who presented with a tender swelling in the right periorbital region (Case 2). A: Contrast-enhanced scan obtained at presentation demonstrating a soft-tissue lesion with bone involvement in the right inferior frontal bone. B: Bone-window scan obtained at presentation demonstrating a nonsclerotic lytic lesion. C and D: Contrast-enhanced (C) and bone-window (D) scans obtained 3 months after presentation demonstrating a decrease in the size of the lesion. $\quad E$ and F: Contrast-enhanced $(E)$ and bone-window $(F)$ scans obtained 19 months after presentation demonstrating complete resolution of the lesion. 

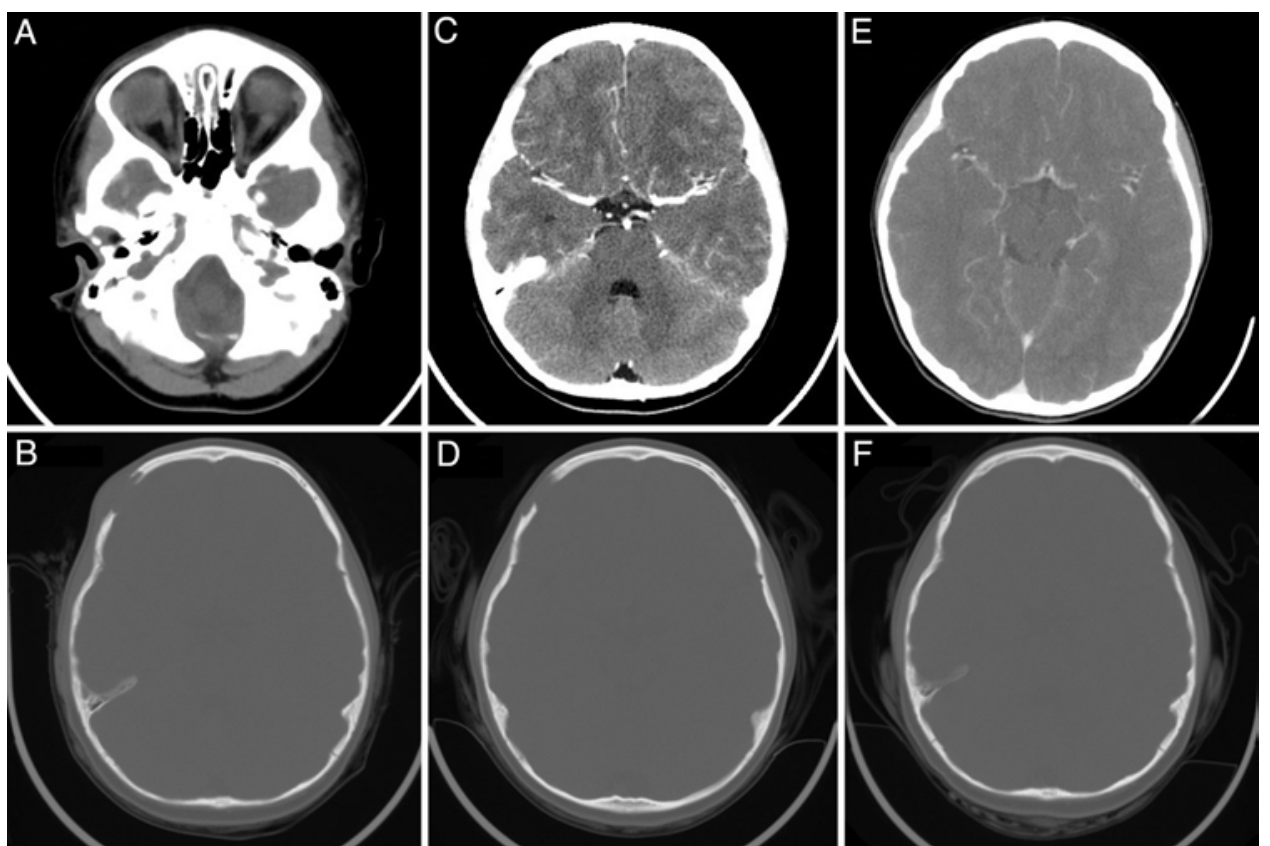

FIG. 2. Serial CT scans obtained in a 4-year-old girl who presented with a tender swelling in the right frontal region (Case 1). A: Contrast-enhanced scan obtained at presentation demonstrating a soft-tissue lesion with bone involvement in the right frontal bone. B: Bone-window scan obtained at presentation demonstrating a nonsclerotic lytic lesion. C and D: Contrastenhanced (C) and bone-window (D) scans obtained 7 weeks after presentation demonstrating a decrease in the size of the lesion. $\quad E$ and $F$ : Contrast-enhanced $(E)$ and bone-window $(F)$ scans obtained 15 months after presentation demonstrating complete resolution of the lesion.

tosplenomegaly, soft-tissue tumor growth (subjective assessment), worsened pain, or neurological deficit.

The main drawback in using this approach is that the diagnosis of EG is based on the radiological findings. The differential diagnosis could include many benign as well as malignant conditions, such as bone cysts, hemangiomas, epidermoid cysts, fibrous dysplasia, osteomyelitis, or metastatic lesions. Those conditions would not spontaneously improve. Additionally, LCH can have some unusual radiographic features. ${ }^{6}$ In this study, observation was a safe strategy and enabled 7 of 8 children to avoid an operation when their lesion resolved completely or almost completely without intervention.

\section{Conclusions}

We report 8 cases of solitary calvarial EG that were managed with observation (Table 1). Only one required surgical intervention. A short period of observation may be useful in the initial management of solitary calvarial EG to avoid a surgical procedure. The decision to proceed with surgery may be based on the severity of symptoms and the nature of the lesion on follow-up imaging. Because this was a retrospective study, there was no standard of care for surveillance. We acknowledge that this is a weakness of this paper, but we have submitted to our IRB a proposal for a prospective study for the nonoperative management of suspected EG of the skull. We anticipate that this will lead to a multicenter prospective trial to observe patients with solitary calvarial EG to confirm our findings and, more importantly, determine guidelines or indications for surgery in these cases.

\section{Disclosure}

The authors report no conflict of interest concerning the materials or methods used in this study or the findings specified in this paper.

Author contributions to the study and manuscript preparation include the following. Conception and design: De Angulo, Sandberg. Acquisition of data: Nair, Lee, Ragheb. Analysis and interpretation of data: Sandberg. Drafting the article: De Angulo, Sandberg, Nair, Lee, Ragheb. Critically revising the article: all authors. Reviewed submitted version of manuscript: all authors. Approved the final version of the manuscript on behalf of all authors: De Angulo. Study supervision: De Angulo, Sandberg.

\section{References}

1. Broadbent V, Pritchard J, Davies EG, Levinsky RJ, Heaf D, Atherton DJ, et al: Spontaneous remission of multi-system histiocytosis X. Lancet 323:253-254, 1984

2. Dunger DB, Broadbent V, Yeoman E, Seckl JR, Lightman SL, Grant DB, et al: The frequency and natural history of diabetes insipidus in children with Langerhans-cell histiocytosis. $\mathbf{N}$ Engl J Med 321:1157-1162, 1989

3. Dziegiel P, Dolilńska-Krajewska B, Dumańska M, Wecławek J, Jeleń M, Podhorska-Okołów M, et al: Coexpression of CD1a, langerin and Birbeck's granules in Langerhans cell histiocytoses (LCH) in children: ultrastructural and immunocytochemical studies. Folia Histochem Cytobiol 45:21-25, 2007

4. Greis PE, Hankin FM: Eosinophilic granuloma. The management of solitary lesions of bone. Clin Orthop Relat Res (257):204-211, 1990

5. Gunny R, Clifton A, Al-Memar A: Spontaneous regression of supratentorial intracerebral Langerhans' cell histiocytosis. Br J Radiol 77:685-687, 2004

6. Hindman BW, Thomas RD, Young LW, Yu L: Langerhans cell histiocytosis: unusual skeletal manifestations observed in thirty-four cases. Skeletal Radiol 27:177-181, 1998 


\section{Observation for management of eosinophilic granulomas}

7. Lipton JM, Arceci RJ: Histiocytic disorders, in Hoffman R, Benz EJ Jr, Shattil SJ, et al (eds): Hematology: Basic Principles and Practice, ed 5. Philadelphia: Churchill Livingstone, 2009, pp 747-760

8. Mickelson MR, Bonfiglio M: Eosinophilic granuloma and its variations. Orthop Clin North Am 8:933-945, 1977

9. Mitnick JS, Pinto RS: Computed tomography in the diagnosis of eosinophilic granuloma. J Comput Assist Tomogr 4:791793, 1980

10. Nanduri VR, Bareille P, Pritchard J, Stanhope R: Growth and endocrine disorders in multisystem Langerhans' cell histiocytosis. Clin Endocrinol (Oxf) 53:509-515, 2000

11. Oliveira M, Steinbok P, Wu J, Heran N, Cochrane D: Spontaneous resolution of calvarial eosinophilic granuloma in children. Pediatr Neurosurg 38:247-252, 2003

12. Plasschaert F, Craig C, Bell R, Cole WG, Wunder JS, Alman
BA: Eosinophilic granuloma. A different behaviour in children than in adults. J Bone Joint Surg Br 84:870-872, 2002

13. Rawlings CE III, Wilkins RH: Solitary eosinophilic granuloma of the skull. Neurosurgery 15:155-161, 1984

14. Shelby JH, Sweet RM: Eosinophilic granuloma of the temporal bone: medical and surgical management in the pediatric patient. South Med J 76:65-70, 1983

Manuscript submitted September 27, 2012.

Accepted April 4, 2013.

Please include this information when citing this paper: published online May 10, 2013; DOI: 10.3171/2013.4.PEDS12482.

Address correspondence to: Guillermo De Angulo, M.D., Miami Children's Hospital, NE Suite 121, 3100 SW 62 Avenue, Miami, Florida 33155. email: Guillermo.deangulo@mch.com. 